\title{
Terrestrial laser scanning survey in support of unstable slopes analysis: the case of Vulcano Island (Italy)
}

\author{
Maria Marsella ${ }^{1}$ Peppe J. V. D'Aranno' ${ }^{1}$ \\ Silvia Scifoni $^{1}$ - Alberico Sonnessa ${ }^{1}$. \\ Marco Corsetti ${ }^{1}$
}

Received: 18 October 2014/Accepted: 21 March 2015/Published online: 5 April 2015

(C) Springer Science+Business Media Dordrecht 2015

\begin{abstract}
The capability to measure at distance dense cloud of 3D point has improved the relevance of geomatic techniques to support risk assessment analysis related to slope instability. This work focuses on quantitative analyses carried out to evaluate the effects of potential failures in the Vulcano Island (Italy). Terrestrial laser scanning was adopted to reconstruct the geometry of investigated slopes that is required for the implementation of numerical modeling adopted to simulate runout areas. Structural and morphological elements, which influenced past instabilities or may be linked to new events, were identified on surface models based on ground surveying. Terrestrial laser scanning was adopted to generate detailed 3D models of subvertical slopes allowing to characterize the distribution and orientation of the rock discontinuities that affect instability mechanism caused by critical geometry. Methods for obtaining and analyzing 3D topographic data and to implement simulation analyses contributing to hazard and risk assessment are discussed for two case studies (Forgia Vecchia slope and Lentia rock walls).
\end{abstract}

Keywords Laser scanner $\cdot$ Slope instability $\cdot$ Numerical simulation $\cdot$ Vulcano Island

\section{Introduction}

The quantitative and qualitative assessment of the classification, volume (or area) and spatial distribution of landslides which exist, or potentially may occur in an area, represents the first step to implement a risk analysis. Landslide susceptibility maps can be compiled by using predictive models, contributing to the landslide hazard zoning that also requires an estimate of the frequency of occurrence (Fell et al. 2008). Risk assessment is performed

Silvia Scifoni

silvia.scifoni@uniroma1.it

1 Department of Civil, Constructional and Environmental Engineering, Sapienza University, Rome, Italy 
by studying the evolution of a landslide phenomenon in relation to the exposure of manmade structures and population. Prevention consists primarily in proper land-use policy and mitigation actions. It begins with accurately observing active slopes to identify the landslide susceptibility areas. Risk mitigation actions include a preliminary phase aimed at the collection of information on landslides occurred in the past (Fell et al. 2008). In addition, they require the implementation of adequate monitoring systems using in situ and remote sensing data. In this way, the identification of areas prone to landslide events and the simulation of potential failures can be addressed.

Flanks of active volcanic edifices are frequently affected by instability phenomena. In some cases, inhabited areas have progressively approached active unstable slopes, increasing the risk linked to possible failures that, at the onset of volcanic phenomena, can occur much faster and more unexpected than other volcanic events (McGuire 1996). Therefore, active volcanic areas deserve attention also during quiescent period since the probability of failure is increased by hydrothermal activity that contributes to weaken the volcano flanks. At coastal volcanoes, a further hazard is related to the tsunami waves that can be generated by the propagation of the landslide mass into the sea. This work is focused on two areas on the island of Vulcano (Aeolian Islands, Italy) where instability processes have already occurred: the slope of the Forgia Vecchia (FV) and the Lentia Complex (LC) (Fig. 1). The sites were chosen as test cases to demonstrate how 3D surveying techniques can support surface data collection in order to investigate on instability mechanisms and to contribute to the evaluation of potential destructive scenarios.

FV site is situated on the northern-east flank of the subaerial part of the La Fossa volcanic edifice (a pyroclastic cone of about $240 \mathrm{~m}$ high and a base diameter of $\mathrm{m}$ at sea level of $2000 \mathrm{~m}$ ). It corresponds to the vent of the eastern flank of La Fossa that steeply dips toward the sea and has already undergone landsliding of rock volumes that entered in the sea causing tsunami waves. An example of this type of event is the landslide occurred in 1988 (Fig. 1) that produced waves few meters high to the harbor area along the northeast side of the Island (Tinti et al. 1999). The northern flank of La Fossa, partially formed by altered pyroclastic materials, is prone to rock falls, rock slides and debris slides. In most cases, the potentially unstable areas are delimited by tension cracks where high-temperature volcanic gases flow through. Since the slope overlooks an area where most of resident and touristic facilities are located, potential failures represent a major concern for civil protection. Terrestrial laser scanning (TLS) surveying techniques can be effectively used to update the current geometry of the slope and through multi-temporal datasets, adopted to identify and quantify recent failures, to understand the activity of the slope. The reconstruction of a complex 3D model of the surface contributes to simulate potential destructive behavior of a slope through a numerical analysis approach. In order to improve the reconstruction of the subhorizontal portions of the slopes, the 3D model obtained from the TLS point cloud was integrated with data of comparable accuracy, obtained by means of Aerial Laser Scanning (ALS) and Digital Photogrammetry (ADP) surveys (Marsella et al. 2009).

The Lentia rock walls were often interested by instability processes, whose effects are still clearly visible in the form of detachment areas and fractured blocks distributed along the overlooking valley. These phenomena have strong variability in their kinematic mechanisms, which may lead to sudden failures associated with high speed and long runout distance. The sizes of the detachable rock masses are quite large; therefore, effective actions to reduce the risks are complex and expensive. In these conditions, the design of prevention actions can benefit from data able to provide accurate $3 \mathrm{D}$ models of the rock walls for the implementation of numerical models and to locate and measure the most 


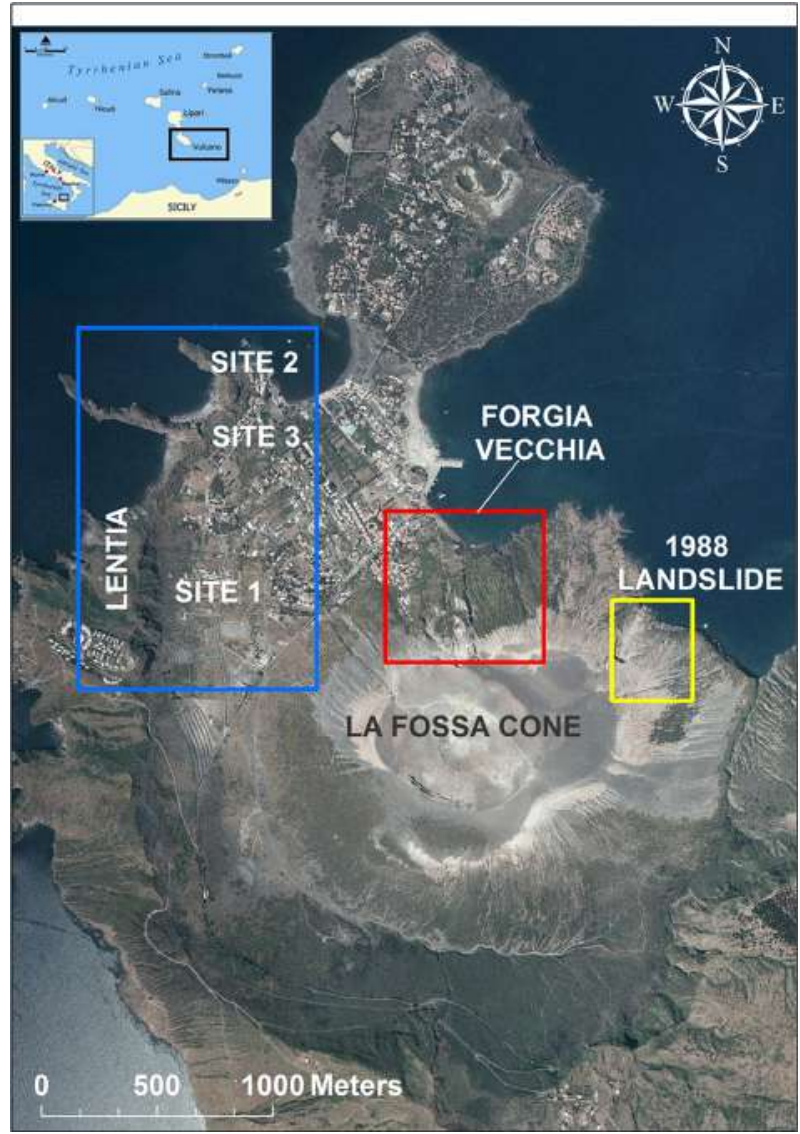

Fig. 1 Orthophoto map of the Vulcano Island showing the areas affected by instability processes: red box indicates the Forgia Vecchia area, blue box delimits the three test sites along the Lentia complex, and yellow box locates the 1988 landslide zone

critical features. In this context, TLS surveying furnish a valid contribution provided that the measurements are acquired periodically and adopted also to calibrate numerical models by means of a back analysis approach. TLS data are also useful to extract the geomechanical parameters on the whole the wall surface describing the geometry of the rock discontinuities (Abellán et al. 2013).

\section{Methodology}

\subsection{TLS data acquisition and processing}

Terrestrial laser scanning (TLS) is a recently developed technique for 3D land mapping that supports a large variety of geomatic applications in different fields. The laser scanning sensor used in this work is based on the measurement of the "time of flight (TOF)" 
performed by a laser diode that sends a pulsed laser beam along prefixed scan lines to the investigated object. The pulsed laser beam diverges through a polygonal mirror with a number of reflective surfaces inside the instrument. The pulse is diffusely reflected by the incident surface and part of the light returns to the receiver. The time that light needs to travel from the laser diode to the object surface and back is measured very precisely. Beam deflection mechanism provides elevation and azimuth of the transmitted pulse. Using the distance from the scanner to the object and knowing the azimuth and elevation of the beam, it is possible to calculate the position of each reflective point. The survey yields a numerical dataset, which is essentially a dense "point cloud" where each point it is represented by a set of coordinates in $3 \mathrm{D}$ space $(\mathrm{X}, \mathrm{Y}$ and $\mathrm{Z}$, in local reference system with origin in the center of the scan station) and the reflected intensity (I) of the laser beam. A very high density of points can be achieved by having a spatial resolution in the order of 5-10 mm, depending on the distance from the object and on the instrument characteristic. Commonly used scanners have a range of acquisition that varies between 100 and $2000 \mathrm{~m}$ and a scanning speed of 2000-200,000 pts/s (Pirotti et al. 2013a). The accuracy of the points increases as there is a decrease in the distance for the object and its reflectivity.

Based on parameters set up by the operator in function of the size of the area of interest and of the requested spatial resolution, the instrument acquires a cloud of $3 \mathrm{D}$ points having a density which varies with the frequency rate, the number of scans and the scan stationobject distance. The acquisition software creates a project file for each dataset, which contains the setting parameters, the raw data scans and the associated digital images. It also allows to control the coverage and overlap of scans, to perform a preprocessing step (removal of noise and registration of scan), to process filtered data (creating a solid model) and to integrate other data for creating a textured model. More specifically, the preprocessing step includes the point cloud filtering, co-registration and georeferencing. The filtering procedure consists in the elimination of outliers and in the removal of points not belonging to the investigated surface, such as cables and vegetation (Pirotti et al. 2013b). Co-registration is aimed at recording all the different clouds of points in a unique reference system, reducing the effects of systematic errors (translation and rotation) due to the different orientation of the acquisition views. The co-registration is performed by including artificial reflecting targets of known position (to be used also for georeferencing) and by identification corresponding natural targets from different scan stations by means of automatic image correlation techniques. For mapping purposes, 3D modeling is usually carried out interpolating the point cloud by using the interpolation method, able to produce a regular spaced grid DTM from irregularly spaced data. Further data analysis can be performed on the TLS products, depending on the field of application. As described in the following paragraph, in case of TLS surveys of a rock wall the extraction of geo-mechanical parameters of the discontinuities in the rock surfaces can be performed using an interactive semi-automated approach based on automatic selection of the discontinuities, integrated by an expert manual supervision. In addition, the volume of unstable blocks can be estimated after having created a complex 3D mesh representing a detailed morphological model of investigated areas.

In this work, a terrestrial Laser Scanner RIEGL LMS Z210i (Table 1) combined with a calibrated digital camera (Nikon D70s) was adopted. The collected data were processed by means of RiscanPro software (Riegl et al. 2003) and integrated with data available from previous ALS and ADP surveys to describe subhorizontal surface that are usually not detectable from TLS scan positions. 
Table 1 Technical characteristic of the Laser scanner used in the survey

\begin{tabular}{ll}
\hline & Riegel laser scanner Z210i \\
\hline Field of view & Vertical: $90^{\circ}$ \\
& Horizontal: $360^{\circ}$ \\
Maximum range & $1000 \mathrm{~m}$ \\
Digital camera & Nikon D70s \\
Resolution range & $5 \mathrm{~mm}$ \\
Resolution & $0.002^{\circ}$ \\
Beam divergence & $0.25 \mathrm{mrad}$ \\
Data acquisition rate & $12.000 \mathrm{pixel} / \mathrm{s}$ \\
\hline
\end{tabular}

\subsection{Numerical modeling of landslide propagation}

The mechanisms causing slope instability are quite complex to be modeled. They depend on many factors, such as the presence of structural discontinuities, geometry of the rock walls and mass involved in the movements, triggering effects (precipitation, overloads, seismic activity, etc.). Therefore, the prevision of time and magnitude of an instability process implies the use of advanced numerical models. In case of slope and rock walls that have recently experienced instability process or show clear evidence of potential failures, the estimation of the potential volumes of the detachments and of its distribution along overlooking area, it is the first step to assess whether more advanced analysis needs to be implemented. In particular, it is difficult to precisely establish the travel distance and the invasion area. In this study, two different types of landslide were analyzed: a debris flow that is a rapid mass movement of mixture of granular solids, water and air and a rockfall characterized by failures and detachments of rock fragments followed by downward motion (Varnes 1978).

For simulating the propagation of the debris flow after the detachment, a dynamic model dynamic analysis of landslides in three dimensions (DAN 3D) based on a numerical solution of motion equations was employed: it allows to estimate the landslide runout, velocity, thickness and the distribution of debris in the deposition area at different epochs. The numerical model was developed by McDougall and Hungr (2004) for the dynamic analysis of rapid flow slides and debris flows. DAN 3D requires input describing (1) the topography, (2) the geometry of the source and (3) rheological parameters. Topography is included in the form of grid file, namely "path topography file," describing the ground surface that was obtained integrating the TLS surveys and ALS DTM, as described in the previous chapter. The geometry is inserted through a "source depth file" that includes the volume and the shape of the identified failure (Fig. 4a, b). A better estimate of the geometry and the volume of the potential landslide body can been evaluated by performing stability analysis, using a 3D limit equilibrium, that also allows to estimate the critical slip surface (Duncan 1996). Finally, the rheology can be defined selecting among different constitutive models (McDougall and Hungr 2004). In our analyses, we adopted a combination of a frictional rheology, considered more realistic in case of sliding masses that remain dry during the path, and a Voellmy rheology (Voellmy 1955), that could better depict the dynamic behavior of the avalanche in the upper portion where wet material is more likely to be incorporated into the moving mass.

The rockfall simulation was carried out using 2D and 3D kinematic models for providing the paths of maximum advance and the areas affected by potential failures of rock 
blocks, respectively. The CRSP-2D code (Pfeiffer and Bowen 1989a, b) was used for evaluating the runout distance of potential rock fall events at the base of a slope. The input data include the slope profile, the shapes and volumes of the detachable rock blocks. The ROTOMAP software (GEO\&SOFT 2002) was adopted to define the areas potentially affected by the rock falls. The software implements a 3D model based on a statistical approach that it is able to simulate a large number of rock falls, through the analysis of the distribution of the average and maximum kinetic energies. The program requires a detailed topographic map and a geomorphologic data collection to identify the areas where a rockfall can initiate. In this work, these inputs were obtained by integrating both TLS and ALS data.

\section{Case studies on the Island of Volcano}

The Island of Vulcano, belonging to the Aeolian Archipelago located North of Sicily, hosts La Fossa cone located in the northern part of the island (Fig. 1). The subaerial part of La Fossa edifice is a 400-m-high pyroclastic cone with a base diameter of $1200 \mathrm{~m}$ at sea level (De Astis and La Volpe 1997). The cone overlies the materials filling the caldera and generated by the collapse of the northern part of the island (Keller 1980). With the exception of the FV parasitic crater on the northeastern sector, the cone is regular as a whole with slopes in the order of $40^{\circ}$. Continuous fumarolic activity through fractures has determined a diffuse mineralization, conferring a higher consistency to the pyroclastites, which around fractures appear stiff and hard. Degassing, both concentrated along fractures and widespread over relatively large areas, displays recurrent periods of "unrest" characterized by larger vapor release. Different types of instability processes were recognized on La Fossa cone (Tommasi et al. 2007). Far from paroxysmal phases, the past instability events (documented or recognizable by morphological evidences) are slides occurred along layers of pyroclastite (1988 landslide, $193,000 \mathrm{~m}^{3}$ in volume), planar slides over the whole slope of the cone and slumping/toppling along the upper rim of the FV crater (Baldi et al. 2006). Occurrence of these events is increased by seismic actions, magmatic inflation and pore pressure changes during the intensification of the volcanic activity (unrest periods).

\subsection{Forgia Vecchia slope}

On the NW sector of La Fossa cone, a large depression in correspondence of FV crater rim is clearly visible in Fig. 1, representing the first case study of this work. In order to reconstruct the geometry of this unstable slope, a multi-temporal dataset formed by ALS, ADP and TLS data having different coverage and resolution were analyzed (Table 2). ADP data acquired in 2001 (Baldi et al. 2006) provided a 1:5000 scale orthophoto and a $1 \times 1 \mathrm{~m}$ grid digital terrain model (DTM) that we updated using an ALS DTM acquired in

Table 2 Available data, year and spatial resolution

\begin{tabular}{lll}
\hline Type of available data & Year & Spatial resolution (m) \\
\hline ADP Orthophoto/DTM & 2001 & $0.35 / 1$ \\
ALS DTM & 2008 & 1 \\
TLS DTM & 2009 & $0.5 \times 0.5$ \\
TLS DTM & 2012 & $0.5 \times 0.5$ \\
\hline
\end{tabular}


2008 of the whole island (furnished by Ministry of the Environment). The TLS data, acquired in 2009 and 2012 using a RIEGL Laser Scanning (Table 1), were integrated with the aerial datasets in order to improve the 3D model along the subvertical slopes.

The TLS data were acquired from three different scan positions that were combined through a set of nine common tie points. The co-registration procedure provided residual errors of about $0.02 \mathrm{~m}$ that can be assumed as reference for internal accuracy of the TLS data.

The final point cloud were filtered to remove the outliers and interpolated to obtain a grid DTM. The TLS DTM was georeferenced in WGS84 reference system measuring a number of tie points with a GNSS survey in RTK acquisition mode that is characterized by an accuracy of about $0.2 \mathrm{~m}$ in the $3 \mathrm{D}$ components. The final mapping accuracy of the georeferenced TLS DTM is at the decimeter level. The final 3D model was obtained integrating the TLS and ALS DTM (Fig. 2) and was used to reconstruct the geometry of the flank and to identify structural and morphological elements linked to past instabilities, as described in the following paragraphs. In order to detect possible recent failures in proximity of the FV slope, we analyzed the residual map that describes the difference in the height component observed between 2001 and the 2012 (Fig. 3). This map highlights localized instabilities phenomena that were probably linked to movements along the lateral and back surface of the whole landslide area as a result of erosive processes caused by weathering of the rock exposed to fumarolic activity.

\subsubsection{Simulation of a landslide}

The definition of the possible failure geometry was aided by the positions of fractures formed behind the rim edge, as indicated in Fig. 4a, b. The presence of a large fracture in the back of the edge of Forgia Vecchia and the morphological features that constrain the lateral extents were taken into account.

The values of geotechnical parameters were based on literature data for materials of similar characteristics that compose the edge of Forgia Vecchia (Tommasi et al. 2007). The limit equilibrium analysis, which allowed identifying critical surfaces on different hypotheses about the limits of the landslide body, is described in Marsella et al. (2011). In this work, a potential landslide volume of about 22,600 $\mathrm{m}^{3}$ (Salino 2009) was considered.

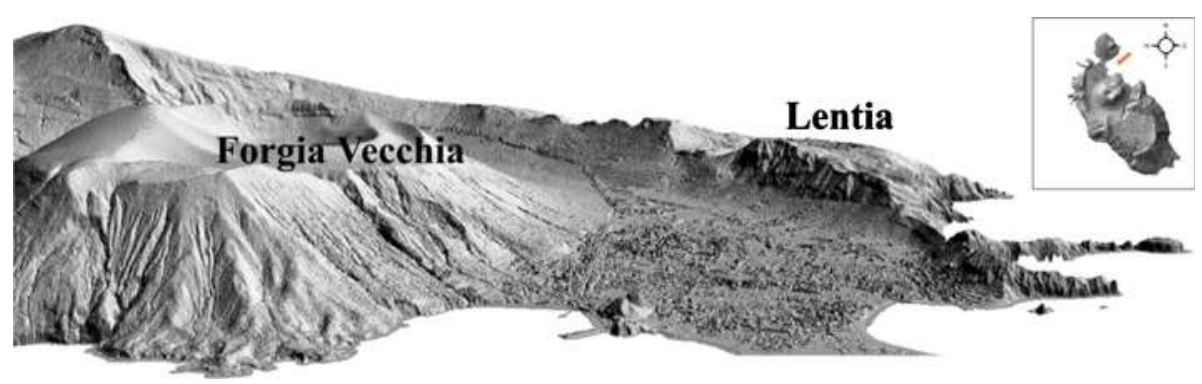

Fig. 2 3D view of the shaded relief map from the NE of the slopes evidencing the areas where the analysis for assessing the potential instability phenomena is conducted: the Forgia Vecchia area and the Lentia rock wall complex 

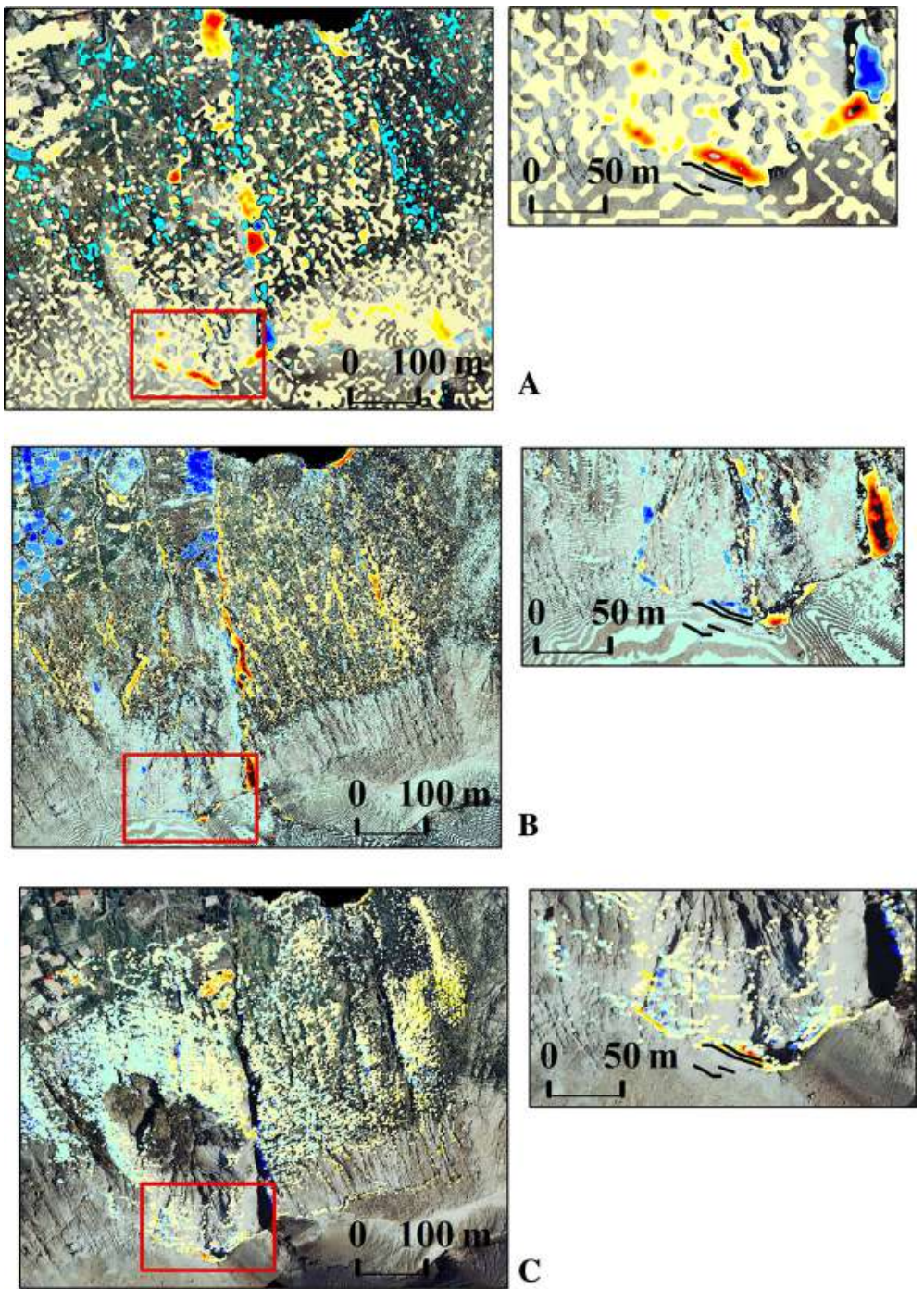

\section{Residual (m)}

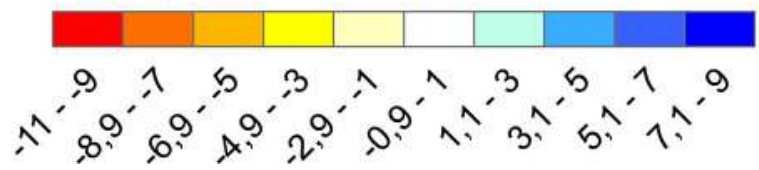

Fig. 3 Residual maps showing the observed difference in the vertical component as obtained comparing multi-temporal digital terrain models in the depression area of the Forgia Vecchia: a 1996 AP DTM- 2001 AP DTM; b 2001 AP DTM- 2008 ALS DTM; c 2008 ALS DTM- 2009 TLS DTM (see Table 2). On the right side the detailed views, corresponding to the red insets, evidence the presence of failures along the fractured areas (black lines) that mark the back of the edge of Forgia Vecchia 

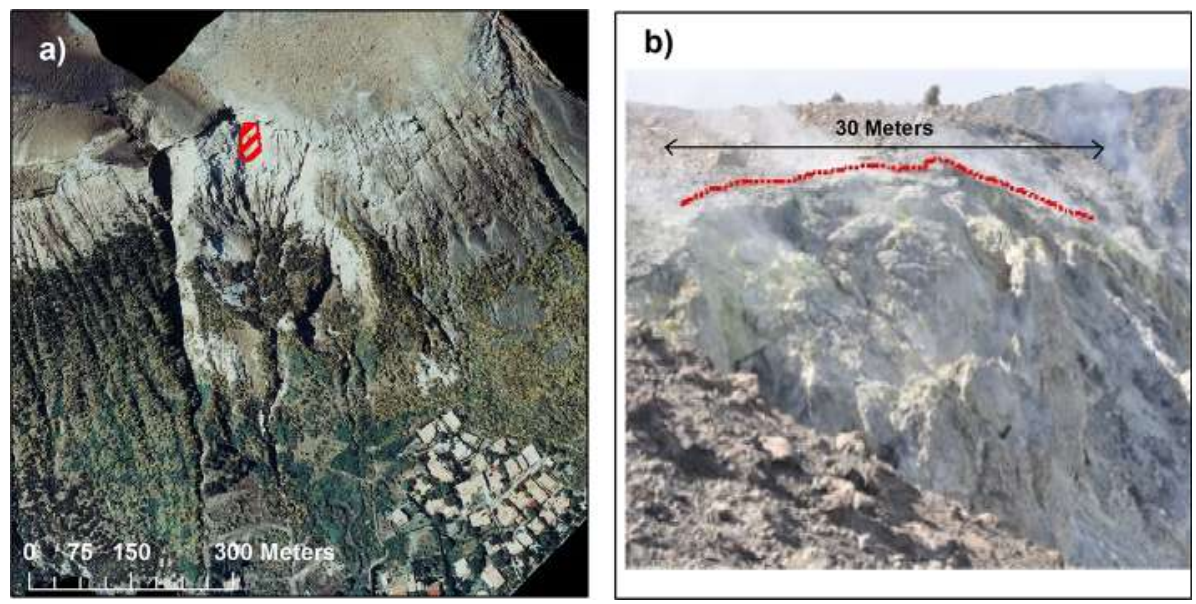

Fig. 4 Characteristics of the movement simulated using the numerical model DAN 3D: a high-resolution orthophoto of the Forgia Vecchia, showing the location of the failure area (in dashed red) in respect to the inhabited area downslope; $\mathbf{b}$ images of the summit area overlooking the Forgia Vecchia crater where dashed red line indicates a major tension fracture corresponding to the back of the edge of the simulated mass movement

Taking into account the rheology, two analyses were conducted, the first using the frictional rheology and the second introducing the Voellmy rheology to model the slope sector between 140 and $0 \mathrm{~m}$ a.s.l. (Table 3).

Figure 5 shows the results of model, plotted on a 3D view at two different time steps, for both the frictional and frictional-Voellmy rheology. The figure evidences how at the same instant the mass involved in the potential landslide is differently distributed, both in area and thickness. In particular, the frictional analysis depicts a faster avalanche rate in the first part that follows the slope morphology but has a lower areal impact respect to the frictional-Voellmy case.

\subsection{The Lentia complex}

The Lentia complex is one of the four main structural and litho-stratigraphic units of the Island. It is the remnant of a larger structure located in the northwestern sector of Vulcano formed between 24 and $15 \mathrm{ka}$ and lately cut by the western ring fault of the Fossa Caldera (De Astis et al. 2006). Along the slope, rock falls have occurred several times as evidenced by the presence of large distributed rock blocks at the foot of the slope. Two laser scanner surveys were performed in 2009 and 2012 to reconstruct the geometry of the rock walls of

Table 3 Rheological parameters used in the landslide simulations where $\gamma$ is the unit weight, $\varphi$ is the frictional angle, $\varphi$ int is the internal frictional angle, $\xi$ is the turbulence coefficient and $\mu$ is the frictional coefficient

\begin{tabular}{llllll}
\hline Rheology & $\gamma\left(\mathrm{kN} / \mathrm{m}^{3}\right)$ & $\varphi\left(^{\circ}\right)$ & $\varphi$ int $\left(^{\circ}\right)$ & $\xi\left(\mathrm{m} / \mathrm{s}^{2}\right)$ & $\mu$ \\
\hline Frictional & 15 & 12 & 34 & & \\
Frictional + Voellmy & 15 & 12 & 34 & 500 & 0.15 \\
\hline
\end{tabular}

The last two parameters are defined only for Voellmy rheology 

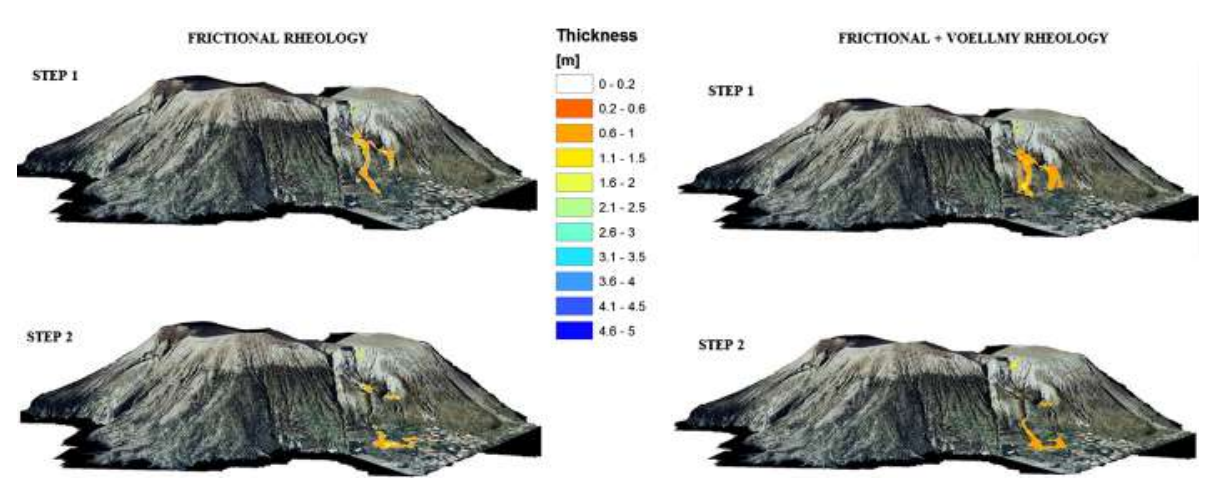

Fig. 5 Two different time steps of landslide simulations plotted on a 3D view of Vulcano Island using frictional (on the left) and frictional + Voellmy rheologies (on the right)

Mt. Lentia from three different scan positions, thus allowing analyzing the three different portions shown in Fig. 1 (site 1-2-3). After having co-registered, georeferenced and filtered the point clouds a DTM of the walls was extracted. The collected data were useful for two purposes: the quantitative evaluation of the state of fracturing, assessed through the measurements of the extension and spacing of the discontinuities in the rock mass, and the identification and estimation of the volume of potentially unstable blocks necessary to perform rock fall simulations.

The quality of the rock mass is evaluated by analyzing the extent and spacing parameters of the most significant discontinuities. Both parameters maybe adopted to assess whether adjacent discontinuities delimit, or not, large portions of potentially unstable rock. It is important to highlight that the rock families characterized by large extension values, that is discontinuity developing along the whole walls, are those potentially interested by detachments of large rock volumes, especially if they are crosscut by subhorizontal discontinuities. Usually, these parameters are measured by geological engineers along selected sections and are limited to the visible discontinuities when it is not possible to climb on the wall. On the contrary, by using the TLS data it is possible to perform an overall quantitative analysis of the state of fracturing of the whole rock wall. This method, despite a possible loss of accuracy compared with direct measurements that depends on the spatial resolution of digital images and point clouds, provides a more comprehensive evaluation of fracturing and discontinuities in jointed rocks and permits also to obtain quite reliable estimates of the volumes of potential unstable blocks. It worth to remark that this type of analysis can be conducted in the laboratory and at the scale of the whole rock mass, included the inaccessible areas.

TLS data were post-processed using RiscanPro software that permits to digitize the significant discontinuities identified on the point clouds and to estimate coefficient of planar surfaces. This step is aided by the analysis of digital images and shaded relief maps obtained for the subvertical walls of slope. The discontinuities form a polyline datasets useful to perform the geometrical analysis. The polylines are projected on an average plane $(\alpha, \beta, \gamma$ Site 1) interpolating the irregular surface of the rock walls (Fig. 6a, b) where the length of each discontinuity (extent) along the walls and the distance between consecutive pairs (spacing) at different elevation (Fig. 6c) are estimated. By considering the spacing, the orientation and the continuity of detected discontinuities, potential unstable blocks are identified. The size and the shape of each block are estimated after having interpolated the 


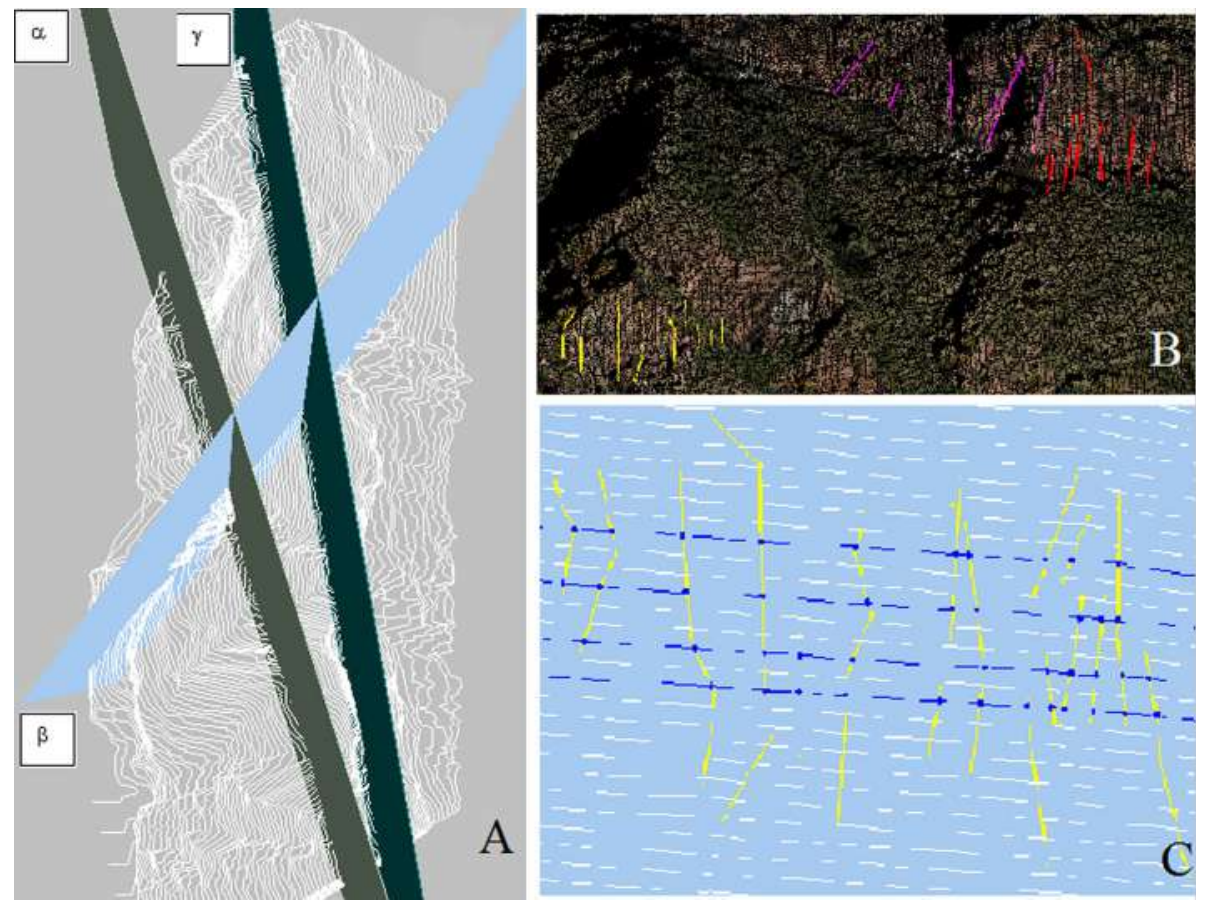

Fig. 6 Example of the geometrical setting adopted for measuring the spacing parameter based on selected planes that interpolate the irregular surface of separated front: a 3D contour line map of site 1 on which three different interpolating planes represent the three analyzed portions of the wall ( $\alpha$ and $\beta$ are referred to the upper right zone while plane $\gamma$ is referred to bottom left zone); $\mathbf{b}$ discontinuities referred to three identified planes marked in different colors (red for $\alpha$, violet for $\beta$ and yellow for $\gamma$ plane respectively); c an example of discontinuities projected on the selected plane used for measuring the distance between consecutive pairs (spacing) at different elevation

point cloud to obtain a surface formed by triangular mesh, usually preferred to describe complex surfaces.

By using the methodology described above, three sites of the Lentia complex were analyzed (Fig. 7). Site 1 that interests a area of approximately $80 \mathrm{~m}$ height and about $200 \mathrm{~m}$ width was further separated in two parts, characterized by different states of fracturing (Fig. 8a, b). The complexity of this site depends on possible overlaps of fracturing process of volcano-tectonic origin affecting highly viscous lavas. Sector A appears more irregular, while the sector B shows a quite regular fracturing characterized by a series of subvertical discontinuities that are clearly visible in the TLS data (Fig. 8). Site 2 (having a height of approximately $50 \mathrm{~m}$ and width of about $120 \mathrm{~m}$ ) presents a very irregular and intense fracturing typical of cooling processes (Fig. 9a, b). In the central part of the wall, subvertical discontinuities appear more regular and extended. Site 3 (having a height of approximately $30 \mathrm{~m}$ and width of about $50 \mathrm{~m}$ ) presents a variable state of fracturing (Fig. 9c, d). The results are summarized in Table 4 that shows the values of the extent and spacing. Figure 7 shows the geometry of critical blocks identified for each site and in Table 5 reports the corresponding volume estimates. 

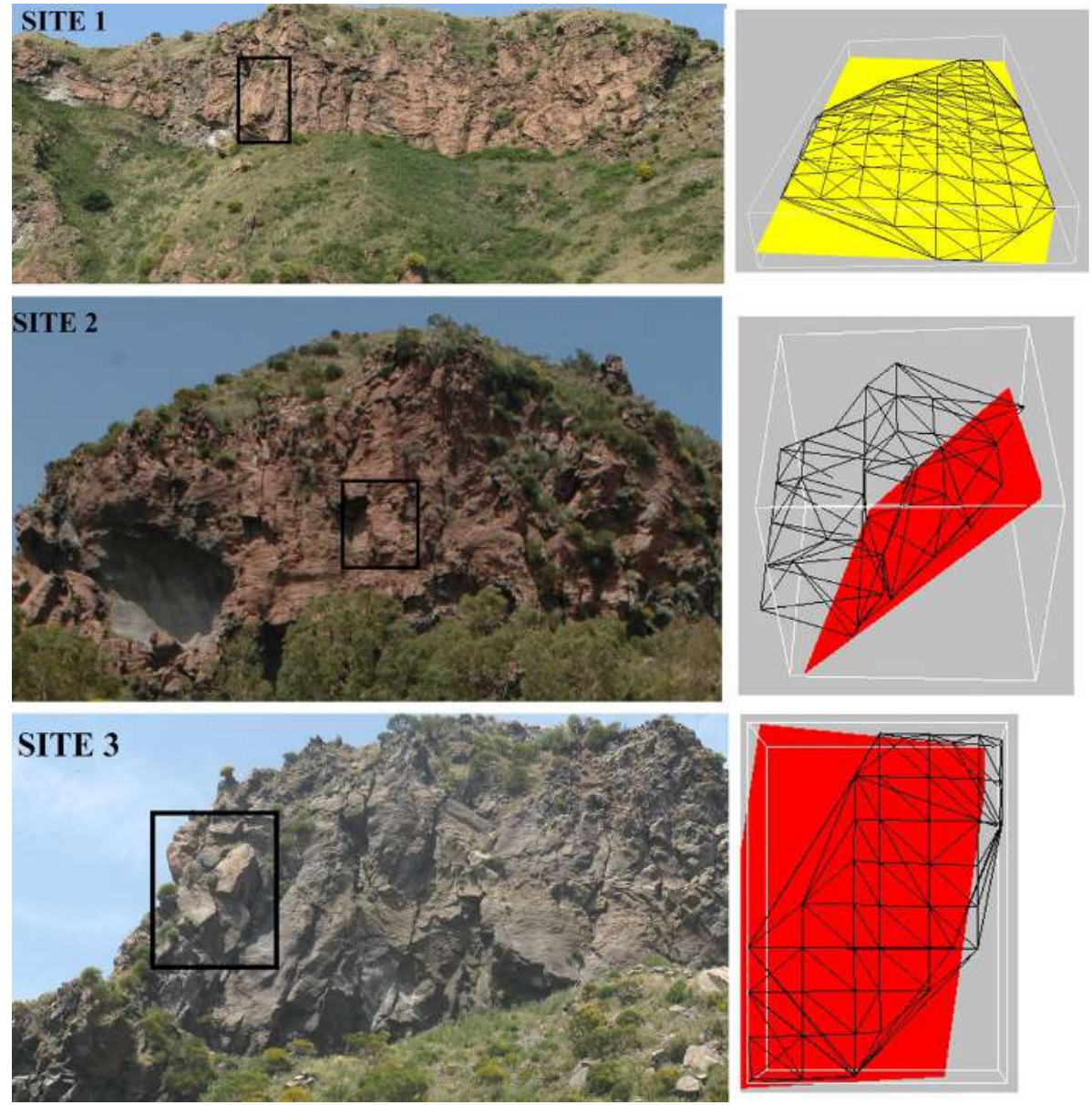

Fig. 7 Locations of potentially unstable blocks in a front view pictures of the three sites and their geometrical reconstruction by a $3 \mathrm{D}$ mesh

\subsubsection{Simulation of a rockfall}

One of the key aspects of the landslide propagation analysis (single blocks or rock avalanches) is the evaluation of the parameters that express the dissipation energy during the motion. For this reason, a back analysis of a past detachment event was performed thanks to the knowledge of the volume, paths and stop positions of detached blocks that were measured on the georeferenced 3D TLS model describing the slope facing the rock walls (Miraglia 2009).

The simulations carried out with the two models (2D and 3D) provided results showing discrepancies in the order of a few tens of meters for the maximum distance reached by blocks. This uncertainty is considered not significant for the assessment of risk scenarios because there are not elements at risk close to runout area. The differences between the 2D and 3D simulations can be also justified by the different way in defining the shape of the blocks. In ROTOMAP, the block is assumed to be a point feature and in CRSP-2D 


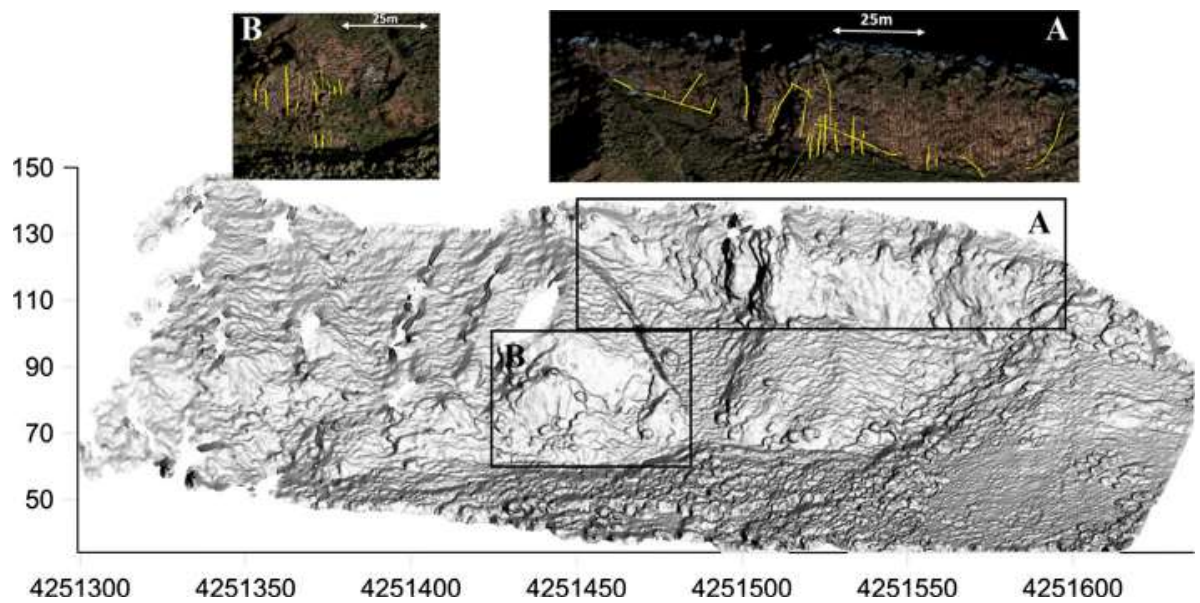

Fig. 8 Site 1: A shaded relief view of grid data where two different rock wall, a, b, are evidenced. On the top the digitized discontinuities are shown on the 2D view of TLS RGB points cloud
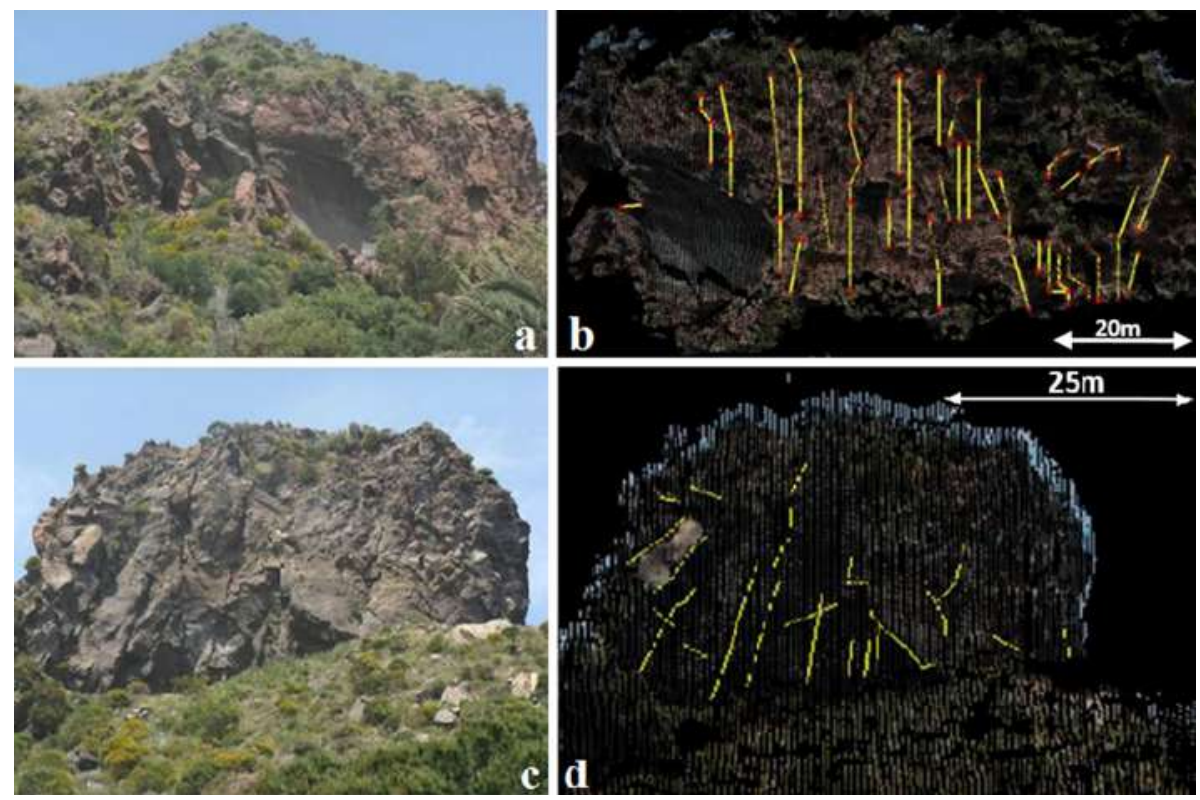

Fig. 9 Images taken from the TLS scan potition and the corresponding 2D views of TLS RGB points cloud with the digitized discontinuities for site $2(\mathbf{a}, \mathbf{b})$ and $3(\mathbf{c}, \mathbf{d})$

spherical body. This means that in CRSP-2D the block can also have a rotational component in the speed, while in ROTOMAP only translational motions are considered. Figure 10a only shows the results in terms of potential trajectories of blocks of the 3D simulations for the three sites.

In Site 1 and 2, two blocks (1 and 2 in Fig. 10a) are potentially impacting on inhabited areas and appear rather dangerous for houses and roads at the foot of the slope. For site 3, 
Table 4 Number of the digitized discontinuities, mean extent and spacing for each site

\begin{tabular}{lccc}
\hline & Number of discontinuities & Mean extent $(\mathrm{m})$ & Average spacing $(\mathrm{m})$ \\
\hline Site 1 & & & \\
A plane $\alpha$ & 8 & 11.8 & 3.0 \\
A plane $\beta$ & 6 & 11.9 & 10.2 \\
B plane $\gamma$ & 10 & 8.8 & 3.1 \\
Site 2 & 18 & 9.4 & 3.0 \\
Site 3 & 11 & 8.3 & 4.2 \\
\hline
\end{tabular}

Table 5 Volume of possible critical blocks for each site
Volume of critical blocks $\left(\mathrm{m}^{3}\right)$

Site 1

20.5

Site 2

27.2

Site 3

121.00

the results obtained from 3D simulation show a block (3, in Fig. 10) that would affect the street below the slope. Such results represent a preliminary step to implement a more rigorous analysis on the potential hazard and may contribute to the design and evaluation of mitigation actions, such as defining the areas of restricted access or the construction of protective structures.

\section{Conclusive remarks}

The presented study illustrates how the combined use of geomatic techniques, mainly TLS aided by ALS and AD, can contribute to the quantitative analysis that is necessary to implement landslide propagation models. Starting from TLS point cloud datasets it is possible to reconstruct a complete detailed DTM of subvertical slopes useful to understand and analyze the geometry of the wall by extracting information on the discontinuities influencing potential mass movements. Two case studies were analyzed in this work: the "Forgia Vecchia" test illustrates the implementation of a runout analysis of the debris avalanche, that might potentially be generated by a failure of the northern flank of La Fossa Cone; the second test focused on Mt. Lentia site describes a procedure for evaluating rockfall propagation starting from a TLS survey.

The DTM obtained merging aerial and terrestrial datasets allowed the identification and measurements of structural and morphological features linked to past failures and provided an updated topographic surface adopted to perform runout analyses using DAN 3D code. Taking into account the rheology, two analyses were conducted, the first using the frictional rheology and the second introducing the Voellmy rheology. The analyses allowed to preliminary assess the potentially inundated area. In particular, the frictional analysis depicts a faster avalanche rate in the first part that follows the slope morphology but has a lower areal impact respect to the frictional-Voellmy case. Future improvements in the model could come from investigation on thickness and moisture conditions of the debris deposit filling the FV crater and on a better definition of the rheological parameters. 

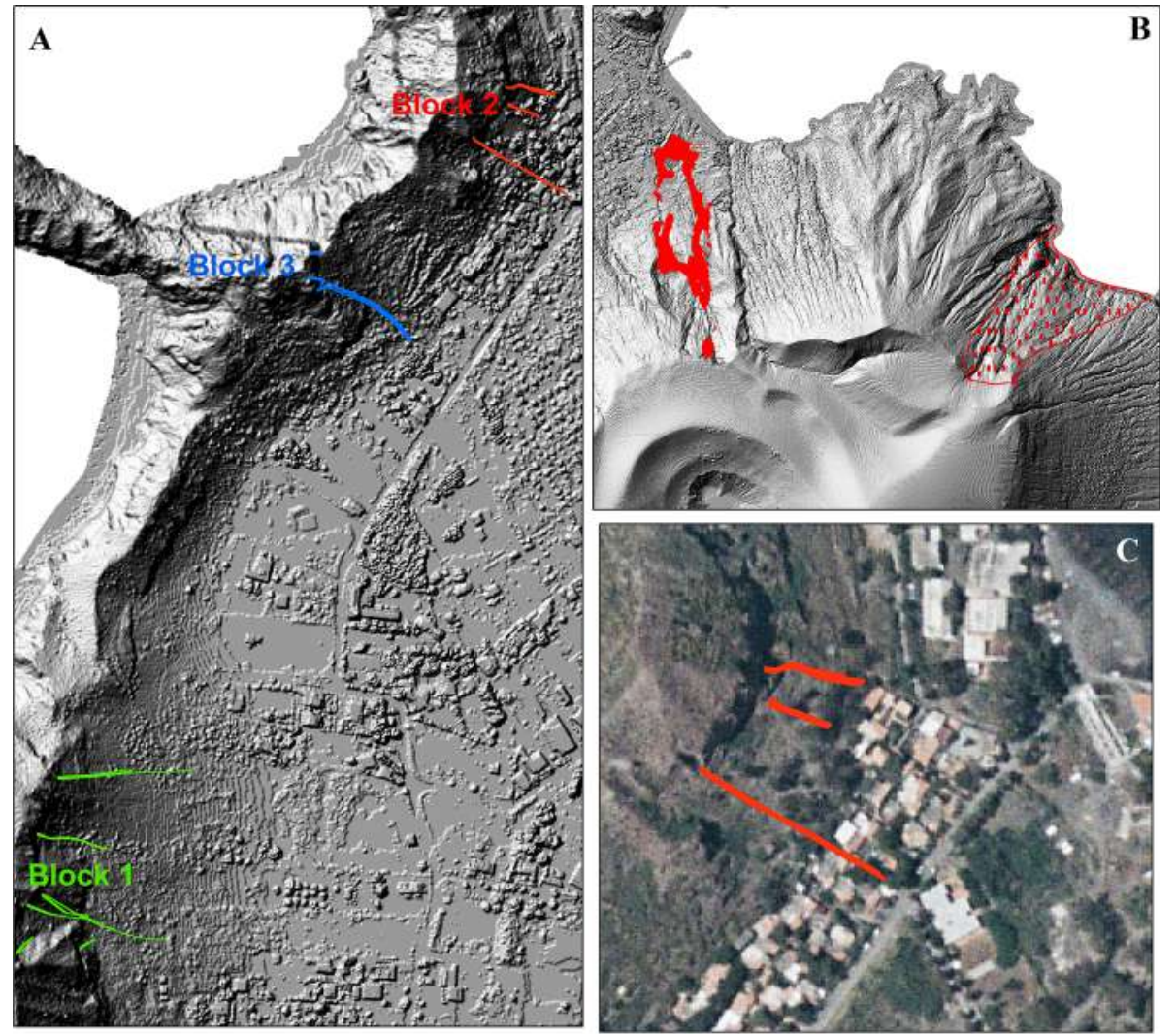

\section{Prediction analysis of instabilities}

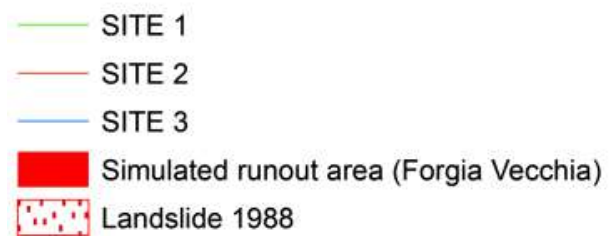

Fig. 10 Results of the simulation analysis carried out for the two test areas: a trajectories of potentially unstable blocks obtained from the rockfall analysis; $\mathbf{b}$ area potentially interested by the runout of the simulated landslide at Forgia Vecchia; c detailed view of the trajectories of falling blocks approaching the inhabited area

In the second case, TLS and digital image supported the analysis of rock and potentially unstable blocks, by a semi-automatic procedure. Simulations were carried out taking into account 2D (CRSP-2D) and 3D kinematic models (ROTOMAP) both providing the paths of maximum advance of rock falls.

Methods for TLS data acquisition, processing and analysis were discussed with the aim of setting up a suitable methodology for measuring parameters influencing the behavior of a rock mass. The integration of TLS data with those obtained from aerial survey allowed generating an accurate DTM that improved the knowledge on morphological 
characteristics of the area. Results from rock mass classification and from a preliminary runout and rockfall analysis highlight some critical features, which may require the execution of precautionary measures. However, the presented modeling must be considered preliminary since it does not include dynamic forces resulting from precipitations, seismic loading and volcanic activity. These considerations, even though deserving further investigations, highlight the importance of a continuous monitoring of the source area in order to record the evolution of deformations at the slope top in time for alerting authorities in charge of civil protection procedures.

Acknowledgments This work was partially supported by the DPC-INGV Project V3 on Vulcano Island (http://sites.google.com/site/progettivulcanologici). We are grateful to Paolo Tommasi of IGAG-CNR who supervised the geo-mechanical surveys and the numerical modeling activities. The 2008 ALS DTM was provided by the Italian Ministry of Environment.

\section{References}

Abellán A, Oppikofer T, Jaboyedoff M, Rosser NJ, Lim M, Lato MJ (2013) Terrestrial laser scanning of rock slope instabilities. Earth Surf Process Landf. doi:10.1002/esp.3493

Baldi P, Fabris M, Marsella M, Monticelli R, Achilli V (2006) Application of digital terrain model to volcanology. Ann Geophys. doi:10.4401/ag-4409

De Astis G, La Volpe L (1997) Volcanological and petrological evolution of Vulcano island (Aeolian Arc, southern Tyrrhenian Sea). J Geophys Res 102(b4):8021-8050. doi:10.1029/96JB03735

De Astis G, Dellino P, La Volpe L, Lucchi F, Tranne C (2006) Carta geologica dell'Isola di Vulcano 1:10 000. L. La Volpe, G. De Astis (eds). doi: 10.1029/96JB03735

Duncan JM (1996) State of the art: limit equilibrium and finite-element analysis of slopes. J Geotech Eng 122:577-596

Fell R, Corominas J, Bonnard C, Cascini L, Leroi E, Savage WZ (2008) Guidelines for landslide susceptibility, hazard and risk zoning for land use planning. Eng Geol 102:85-98. doi:10.1016/j.enggeo.2008. 03.014

GEO\&SOFT (2002) ROTOMAP (http://www.geoandsoft.com)

Keller J (1980) The island of Vulcano. Rendiconti Società Italiana di Mineralogia e Petrologia, 36(1), 369-414

Marsella M, Proietti C, Sonnessa A, Coltelli M, Tommasi P, Bernardo E (2009) The evolution of the Sciara del Fuoco subaerial slope during the 2007 Stromboli eruption: relation between deformation processes and effusive activity. J Volcanol Geotherm Res 182(3):201-213. doi:10.1016/j.jvolgeores.2009.02.002

Marsella M, Salino A, Scifoni S, Sonnessa A, Tommasi P (2011) Stability conditions and evaluation of the runout of a potential landslide at the northern flank of La Fossa active volcano. In: The second world landslide forum, 3-7 Oct 2011, Rome, Italy. doi: 10.1007/978-3-642-31310-3_41

McGuire WJ (1996) Volcano instability: a review of contemporary themes. Geological Society, London, Special Publications 1996, v.110

Miraglia S (2009) Utilizzo della tecnica a scansione laser per l'analisi quantitativa di scenari di rischio: il caso di caduta blocchi da pareti rocciose del Monte Lentia (Isola di Vulcano), Unpublished undergraduate dissertation, Sapienza University of Rome, Italy: 1-190

McDougall S, Hungr O (2004) A model for the analysis of rapid landslide motion across three-dimensional terrain. Can Geotech J 41(6):1084-1097. doi:10.1139/t04-052

Pfeiffer T, Bowen T (1989a) Colorado rock fall simulation programm. Colorado school of mines- US Department of Trasportation Federal Highway Administration, Final Report

Pfeiffer T, Bowen T (1989b) Computer simulation of rockfalls. As Eng Geol Bull XXVI(1):117-126

Pirotti F, Guarnieri A, Vettore A (2013a) State of the art of ground and aerial laser scanning technologies for high-resolution topography of the earth surface. Eur J Remote Sens 46:66-78. doi:10.5721/ EuJRS20134605

Pirotti F, Guarnieri A, Vettore A (2013b) Vegetation filtering of waveform terrestrial laser scanner data for DTM production. Appl Geomat 5(4):311-322. doi:10.1007/s12518-013-0119-3

Riegl J, Studnicka N, Ullrich A (2003) Merging and processing of laser scan data and high-resolution digital images acquired with a hybrid 3D laser sensor. In: proceedings of CIPA XIX international symposium, commission V, WG5, Antalya 
Salino A (2009) Il monitoraggio di fenomeni franosi in aree vulcaniche: il caso del cono La Fossa (isola di Vulcano). Unpublished undergraduate dissertation, Sapienza University of Rome, Italy, 1-140

Tinti S, Bortolucci E, Armigliato A (1999) Numerical simulation of the landslide-induced tsunami of 1988 on Vulcano Island, Italy. Bull Volcanol 61:121-137. doi:10.1007/s004450050267

Tommasi P, Graziani A, Rotonda T, Bevivino C (2007) Preliminary analysis of instability phenomena at Vulcano Island, Italy. Volcanic rocks, Malheiro, Nunes (eds). Taylor \& Francis Group: London, ISBN: 978-0-415-45140-6. doi: 10.1201/NOE0415451406.ch19

Varnes DJ (1978) Slope movement types and processes. In: Schuster R. L. \& Krizek R. J. Ed., Landslides, analysis and control. Transportation research board Sp. Rep. No. 176, Nat. Acad. oi Sciences, pp. 11-33.Voellmy A. 1955. Uber die Zerstorungskraft von Lawinen. Schweizerische Bauzeitung, 73: $212-285$

Voellmy A (1955) Uber die zerstorungskraft von Lawinen. Schweiz. Bauzeitung 73:212-285 